\title{
Mood disorders in elderly patients with chronic obstructive pulmonary disease
}

\author{
Abebaw M Yohannes and Robert C Baldwin \\ Manchester Royal Infirmary, Manchester, UK \\ Martin J Connolly \\ University of Manchester, Manchester, UK
}

\section{Introduction}

Chronic obstructive pulmonary disease is a major cause of morbidity, disability and mortality in old age. ${ }^{1-3}$ The disease is characterized by shortness of breath, impaired ventilatory function and easy fatiguability. These are the most distressing and disabling symptoms of COPD, limiting exercise tolerance, interfering with basic activities of daily living and often, in turn, impairing quality of life. ${ }^{4-6}$

Community surveys in the United Kingdom have reported the prevalence of respiratory symptoms as a potential cause for significant disability in old age at between $30 \%$ and $60 \% .^{7-8}$ Others argue that respiratory symptoms are under-recognized in elderly people, ${ }^{9}$ in whom respiratory conditions are often asymptomatic in their presentation. However, despite this, elderly community-dwellers cite chest problems as a cause of severe disability second only to musculoskeletal disorders. ${ }^{10}$ COPD is a primary cause of death in all age-groups in the UK and four-fifths of all deaths due to COPD occur in individuals aged 70 or older. ${ }^{2}$ It is ranked as the fourth leading cause of death in the US. ${ }^{11}$

The impact of respiratory symptoms on elderly people is complex and affects different aspects of an individual's life. Psychological status plays an important role in maintaining independence in old age. ${ }^{12}$ Undiagnosed and untreated anxiety and depressive symptoms may relate to physical disability, impaired quality of life and increased health care utilization. ${ }^{13-14}$ They may also interfere

Address for correspondence: A Yohannes, Manchester School of Physiotherapy, Manchester Royal Infirmary, M13 9WL, UK. with compliance with medical treatment and accelerate mortality. ${ }^{13,15,16}$ Chronic obstructive pulmonary disease in old age may have a devastating effect. The disease progresses in a subtle way and may gradually incapacitate the patient to a level of dependence in daily activities.

Prevalence of depression and anxiety in elderly patients with COPD

The current review provided the opportunity to conduct a meta-analysis of studies of anxiety and depression in elderly patients with COPD. The aims of this review were to estimate the prevalence of depression and anxiety symptoms and to investigate the consequences in patients with chronic obstructive pulmonary disease. Electronic searches were performed for English citations using the databases, Medline (1966-1998), Psychlit (1984-1998) and Cinhal (1982-1998). The following key words were used: 'COPD', 'depression' and 'anxiety'. The bibliographies of articles so extracted were scrutinized to identify other potentially relevant articles.

Studies were included in the analysis, provided that they included patients with chronic obstructive pulmonary disease as the principal diagnosis and reported the prevalence of depressive and anxiety symptoms in percentage terms. A number of studies were excluded, as they only reported mean scores of depressive or anxiety symptoms. A standard measure of effect size was calculated for each trial and weighted pooled estimates were obtained to estimate the prevalence of depressive symptoms and anxiety in this patient group.

Eleven studies were identified with a percentage score of depressive symptoms and nine studies 
with anxiety symptoms. For all studies with depressive or anxiety symptoms, we performed pooled effect-size analysis giving best estimates of prevalence of depression or anxiety $(95 \%$ confidence limits). The total population studied comprised 900 subjects; the best estimate of prevalence of depression was $40 \%(36-44 \%)$, and for anxiety symptoms (total population 539), 36\% (31-41\%).

Thus in the meta-analysis, combined effect sizes for depressive and anxiety symptoms were very high in this patient group (Table 1) and comparable to those in idiopathic Parkinson's disease or brain damage due to stroke..$^{29,30}$ However, none of the articles reviewed gave details of the effects of treatment on these symptoms. Furthermore, the methodological variation, different assessment tools used and differences in sample populations in the studies examined is acknowledged. Recently van Ede et al. ${ }^{31}$ has addressed these issues in a review which included the articles in this metaanalysis.

In the analysis, most of the studies used screening tools (rather than diagnostic instruments), except two which employed a psychiatric interview using DSM III-R criteria (of the American Psychiatric Association) (Table 1). Screening questionnaires provide an estimate of the prevalence of depressive symptoms and are used to identify potential 'cases' of clinical depression. The prevalence of depressive symptoms in COPD, sufficient to be of clinical importance, range between $7 \%$ and $46 \%$, and that of anxiety up to $49 \%$ (Table 1).

If the problem is so great, why is it often undiagnosed and untreated? Firstly, screening tools for depression or anxiety symptoms are not routinely used in clinical practice. Secondly, symptoms of depression and anxiety in patients with COPD might be masked by physical symptoms, such as decrease in exercise tolerance, breathlessness, fatigue and increased dependence in daily activities. Furthermore, in patients with COPD, poor health, bouts of chest infection and frequent episodes of hospital admission are so common as to be an almost accepted scenario for many patients. In this context, patients may not disclose symptoms of depression or anxiety unless they are specifically asked. ${ }^{32}$ Other contributory factors might be that not all physicians are confident enough to pursue psychiatric assessment and patients may fear approaching their physicians because of the stigma of mental illness. Lack of public awareness fuels this stigma, ${ }^{33}$ and depression itself is associated with its own specific stigma. ${ }^{34}$

\section{The interaction of psychiatric symptoms and COPD}

It has been suggested that untreated depression may interfere with medical treatment and in turn increase health and social service care utilization, leading to higher mortality in the initial phase of hospitalization. ${ }^{15}$ Identification of clinical depression or anxiety thus becomes important in itself. Identification is also needed for optimal management of the older patient with COPD.

Because of the chronic nature of their illness, elderly COPD patients are prone to chest infections, and these and other exacerbations are a cause of frequent hospitalization. Although the effect of this may be difficult to quantify, these are clearly adverse events and impair patients' confidence in their ability to manage their illness, which, in turn, may subsequently produce or exacerbate depressive symptoms. ${ }^{35}$ Previous studies suggest that patients with COPD suffer from disease-related, high 'emotional stress', leading to behavioural changes, such as increased irritability and social withdrawal. ${ }^{36-38}$ Patients tend to employ psychological mechanisms, such as denial or rationalization, to cope and these too may lead to maladaptive behaviour, such as the refusal to go to hospital during an exacerbation. They may also come to fear that any activity will trigger worsening of their breathing difficulties to the point where participation in social activities is completely and irrationally avoided. Thus independence decreases and is replaced by a growing dependence on medical care.

\section{Discrepancy in the reported rates of depressive symptoms}

The lowest prevalence of depressive symptoms was identified by Engstrom et al. ${ }^{25}$ at $7 \%$ and the highest was in our own studies, ${ }^{19}$ at $46 \%$. This huge reported discrepancy may be partly explained by the age group of subjects studied. In the former, the age range was 40-75 (mean 64) years, and statistically there was no difference in the prevalence of depressive symptoms compared to age-sex-matched controls. However, our own 
Table 1. Characteristics of studies

\begin{tabular}{|c|c|c|c|c|c|c|c|c|}
\hline \multirow[t]{2}{*}{ Studies } & \multirow[t]{2}{*}{ Screening tool } & \multicolumn{2}{|c|}{ Prevalence in \% } & \multirow[t]{2}{*}{ Source of subjects } & \multirow[t]{2}{*}{ Mean age } & \multirow[t]{2}{*}{$\mathrm{N}$} & \multirow[t]{2}{*}{ M } & \multirow[t]{2}{*}{$\mathrm{F}$} \\
\hline & & Anxiety & Depression & & & & & \\
\hline $\begin{array}{l}\text { Yohannes } \\
\text { et al. } 1998\end{array}$ & BASDEC & $\mathbf{\square}$ & 46 & Outpatient & 78 & 96 & 56 & 40 \\
\hline $\begin{array}{l}\text { Yellow } \\
\text { et al. } 1987\end{array}$ & DSM III criteria & 34 & 16 & Inpatient & 65 & 50 & 32 & 18 \\
\hline $\begin{array}{l}\text { McSweeny } \\
\text { et al. } 1982\end{array}$ & MMPI & $\mathbf{\square}$ & 42 & Outpatient & 65 & 203 & 160 & 43 \\
\hline $\begin{array}{l}\text { Light } \\
\text { et al. } 1985\end{array}$ & BDI STAI & 2 & 42 & Outpatient & 62 & 45 & $\square$ & $\square$ \\
\hline $\begin{array}{l}\text { Isoaho } \\
\text { et al. } 1995\end{array}$ & ZDS & & 26 & Outpatient & 71 & 83 & 61 & 21 \\
\hline $\begin{array}{l}\text { Borak } \\
\text { et al. } 1991\end{array}$ & BDI MAS & 38 & 79 & Outpatient & 57 & 58 & 34 & 14 \\
\hline $\begin{array}{l}\text { Engstorm } \\
\text { et al. } 1996\end{array}$ & $\mathrm{HAD}$ & 13 & 7 & Outpatient Inpatient & 64 & 68 & 43 & 25 \\
\hline $\begin{array}{l}\text { White } \\
\text { et al. } 1997\end{array}$ & HAD & 40 & 32 & Outpatient & 66 & 44 & 28 & 16 \\
\hline $\begin{array}{l}\text { Eiser } \\
\text { et al. } 1997\end{array}$ & HAD & 55 & $\mathbf{\square}$ & Outpatient & 72 & 18 & 8 & 10 \\
\hline $\begin{array}{l}\text { Bosley } \\
\text { et al. } 1996\end{array}$ & HAD & 28 & 20 & Outpatient & 65 & 93 & 48 & 45 \\
\hline $\begin{array}{l}\text { Jones } \\
\text { et al. } 1989\end{array}$ & HAD & 47 & 29 & Outpatient & 63 & 141 & 92 & 41 \\
\hline $\begin{array}{l}\text { Ries } \\
\text { et al. } 1995\end{array}$ & CES-D & $\mathbf{\square}$ & 24 & Outpatient & 63 & 119 & 87 & 32 \\
\hline $\begin{array}{l}\text { Karajgi } \\
\text { et al. } 1990\end{array}$ & DSM-III- R & 16 & $\mathbf{\square}$ & Outpatient & 65 & 50 & 31 & 19 \\
\hline
\end{tabular}

$$
\begin{array}{ll}
\text { Keys } & \\
\text { HAD } & \text { Hospital Anxiety and Depression Scale } \\
\text { BASDEC } & \text { Brief Assessment Schedule Depression Cards } \\
\text { BDI } & \text { Beck Depression Inventory } \\
\text { MAS } & =\text { Taylor Manifest Anxiety Scale } \\
\text { ZDS } & \text { Zung Depression Scale } \\
\text { MMPI } & \text { Minnesota Multiphasic Personality Inventory } \\
\text { STAI } & \text { State Trait Anxiety Inventory } \\
\text { DSM III } & \text { Diagnostic and Statistical Manual of Mental Disorders } \\
\text { CES-D } & =\text { Centres for Epidemiologic Studies Depression Scale }
\end{array}
$$

not performed or documented

studies investigated older COPD patients aged 70-93 (mean 78) years, and also employed two age-sex-matched control groups in whom the prevalence of depressive symptoms was $26 \%$ (for disabled controls) and $11 \%$ (for normal controls). However, other studies ${ }^{17,18}$ have reported a $42 \%$ prevalence of depression in younger COPD patients, suggesting that age per se is not the main factor accounting for these differences. Other areas thus need exploration, for example, the socio-economic status of the subjects and the validity of the assessment tools used.

Two studies reported that in old age, women tend to report less life satisfaction and higher level of depressive symptoms than men. ${ }^{26,39}$ This may be explained by the greater role loss in women compared to men, when disabled by COPD. Traditionally, women are expected to be homemak- 
ers, care for the family and be responsible for a larger proportion of domestic activities, all of which are severely undermined by COPD. The possible differential effects of gender need to be borne in mind.

\section{Comparisons of depressive symptoms associated with other chronic diseases}

Depression is a common problem for older people. The prevalence of the illness is approximately $10 \%$ for those who are aged above $65 .{ }^{40,41}$ However, for patients who are hospitalized with acute medical conditions, the prevalence ranges from $10 \%$ to $45 \% .^{32}$ In the current meta-analysis, the prevalence of depressive symptoms $(40 \%)$ is similar to that reported in other chronic diseases, such as idiopathic Parkinson's disease (about 40\%), ${ }^{29}$ and higher than that reported in coronary heart disease $(25 \%){ }^{42}$

In studies comparing emotional distress in COPD patients with that of patients with other chronic illnesses, patients with COPD more commonly tend to report feelings of uselessness, loss of social role and decreased libido. ${ }^{36,43}$ Schlenk et al. ${ }^{44}$ investigated six chronic diseases (urinary incontinence, prostate cancer, acquired immune deficiency syndrome, fibromyalgia, hyper-lipidaemia and COPD), and assessed their impact on quality of life, using the Medical Outcomes Study Short Form-36. In this study, COPD subjects had the lowest quality of life in the domains of rolephysical, role-emotional and mental health.

Role loss and what to do with their time is a big problem for many older COPD subjects. Dyspnoea on exertion is the main problem causing subjects to divert their attention towards sedentary activities. In severe hypoxaemic subjects sedentary and more 'intellectual' pursuits may also become a problem because of impaired concentration and mental processing related to hypoxaemia.

\section{Factors that might be associated with depressive symptoms in COPD}

The causes of depressive symptoms in COPD patients are complex. In moderate to severe hypoxemic COPD patients, depressive symptoms seem to be associated with age and low socio-economic status ${ }^{18}$ and closely associated with the degree of physical disability and impairment of quality of life. ${ }^{19}$ Hypoxaemia itself is also associated with impaired quality of life. ${ }^{45}$ The onset of depression has been identified as a risk factor for developing cognitive decline in hypoxaemic COPD patients. ${ }^{46}$

The use of life-prolonging long-term oxygen therapy (LTOT) in the chronic hypoxaemia of COPD may have major implications for patients' everyday life. Some patients feel tied to the oxygen apparatus and become restricted not only outside, but even within the home. Although studies have investigated the efficacy of oxygen therapy in improving functional performance and quality of life, they have not generally addressed psychosocial implications. The recent findings by Monso et al. ${ }^{47}$ confirm that long-term oxygen users suffer severe quality of life impairment and are prone to emotional lability and social isolation. Interestingly, Strom ${ }^{48}$ recently identified that, in male and female patients who use oral corticosteroids with long-term oxygen therapy, women are more susceptible than men to frequent hospitalization and early death.

\section{Are intervention strategies effective in treating anxiety and depressive symptoms?}

\section{Pulmonary rehabilitation}

The British Thoracic Society (BTS) and American Thoracic Society (ATS) guidelines ${ }^{11,49}$ emphasize the need for pulmonary rehabilitation of COPD patients to enhance general wellbeing, improve quality of life and improve independence. Several randomized controlled trials in inpatient and outpatient pulmonary rehabilitation programmes have reported significant improvements in quality of life, reduced symptoms of dyspnoea and increased exercise tolerance. ${ }^{50-52}$ However, very few studies have reported even a meagre improvement in symptoms of anxiety and depression. ${ }^{22,55}$ Possible explanations for this discrepancy include the difficulties of using screening questionnaires (not validated in this patient group) and variability in cut-off points to diagnose a case of depression or anxiety.

Even if they identify depressive symptoms, screening instruments may not be sufficiently sensitive to detect subtle changes during rehabilitation programmes, therefore designing and validating disease-specific scales is worthwhile. 


\section{Psychotherapy and cognitive behavioural therapy}

Eiser et al. ${ }^{21}$ conducted a six-week psychotherapy programme led by a psychiatrist and revealed significant improvement in exercise tolerance but no change in anxiety or depressive symptoms. The programme was aimed at disentangling the root cause(s) of anxiety symptoms from the coping strategies used to overcome problems. Others have claimed success for psychotherapy and relaxation therapy in improving dyspnoea and anxiety symptoms in COPD..$^{53,54}$ It is difficult to determine whether positive effects are specifically due to the type and content of therapy or because of simpler explanations, such as the use of relaxation, or because patients received attention. However, Emery et al. ${ }^{55}$ in three groups of COPD patients, compared the efficacy of (1) exercise training combined with psychotherapy and education (2) education and psychotherapy and (3) education alone. Their findings suggest that those in the first group showed significant improvement in endurance, reduced anxiety and increased cognitive performance, with no improvement observed in the other two groups.

\section{Psycho-education}

A recent meta-analysis by Devine and Pearcy ${ }^{56}$ examined the benefits of psycho-education (exercise training accompanied by education and psychosocial support) in COPD. In seven studies they observed significant improvement in endurance, functional status and psychological wellbeing. In other studies, intensive education for COPD patients has led to significant reduction in health care utilization and also increased knowledge about self-management of the disease, ${ }^{57}$ for example, early patient self-referral to GPs or hospital before the acute exacerbation reaches a severe condition. Others have suggested controlling factors that may trigger acute exacerbation may reduce hospital admission and improve quality of life. ${ }^{58} \mathrm{~A}$ very recent study by Gallefoss et al. ${ }^{59}$ compared patient education of asthmatic and COPD patients. Their findings suggest that education led to significant improvement in quality of life and forced expiratory volume in asthmatic patients, but not in COPD patients. Caution is needed in interpreting the result of this study, as there was wide variation in the age group of the subjects (that of COPD subjects was 57 years, c.f. 41 years for asthmatics). Furthermore, the COPD patients had a longer duration of illness (median 15 years, cf. seven years for asthmatics) and the improvement in $\mathrm{FEV}_{1}$ in the asthmatic group suggests poor control of disease prior to inclusion in the study.

\section{Antidepressant use in COPD patients}

The literature is sparse regarding the use of antidepressants in COPD. Two studies have attempted to examine the efficacy of antidepressants in COPD patients and both were inconclusive. Previously, in a double-blind crossover study, Gordon et al. ${ }^{60}$ compared the efficacy of desipramine with that of placebo in younger age-range COPD patients ( $N=13$, mean age 63 years), with the finding that desipramine was poorly tolerated in this patient group. In this study, seven of the subjects withdrew due to acute exacerbations, side-effects (dry mouth, sleep disturbance, urinary retention, fatigue and tremor) and other concomitant medical problems. Koenig et al. ${ }^{61}$ in a study of medically ill patients had difficulties recruiting subjects because of medical contraindications, such as delirium, bladder outlet obstruction, severity of the overall illness, cancer and patient refusals.

Recently, in this department, the feasibility of using the SSRI fluoxetine in elderly COPD patients has been investigated. Fluoxetine is recognized to be effective and well-tolerated in frail ill elderly

Table 2. Side-effects reported by COPD patients taking fluoxetine

- Nausea

- General tiredness

- Loss of weight

- Tremor

- Dizziness

- Anxiety

- Marked irritability towards family problems 
people. ${ }^{2}$ We recruited 14 elderly COPD patients in an open, single-blinded study of $20 \mathrm{mg} /$ day fluoxetine therapy for six months. ${ }^{63}$ Of these, seven subjects did not complete the study. Five of the subjects withdrew because of side-effects (Table 2 ), one due to family problems and one patient died of a cause unrelated to antidepressants.

However, perhaps the most important finding of this pilot study was the reluctance of patients, identified as depressed by a well-validated psychiatric tool, the Geriatric Mental Status Schedule, ${ }^{64}$ to accept treatment with fluoxetine. Seventy per cent of depressed patients ( $\mathrm{N}=57)$ refused antidepressant treatment, the common reasons for refusal being fear of side-effects, embarrassment, denial of depression, worries about addiction and a frustration with taking 'too many drugs'. Reluctance to accept either the diagnosis or treatment for depression has been previously reported in elderly patients with depression associated with other chronic medical conditions. ${ }^{61}$

\section{Psychiatric co-morbidity (depression plus anxiety) in COPD}

Depressive and anxiety symptoms are common in COPD patients (Table 1). These studies, however, did not investigate the overlap between anxiety and depressive symptoms. In a pilot investigation in this department, ${ }^{65}$ the overlap of anxiety symptoms with depression in elderly patients with COPD was further explored. In the same group of depressed elderly COPD patients $(\mathrm{N}=57)$ described above, the prevalence of anxiety symptoms was found to be $34 \%$, whereas in nondepressed patients $(\mathrm{N}=80)$, it was only $5 \%$. This suggests a striking association between symptoms of depression and anxiety. Caution is needed in the interpretation of these findings, not least because the subjects studied were residents of the inner city, where socio-economic problems are often prevalent. Furthermore, this cross-sectional study cannot say to what extent the anxiety and depressive symptoms arose simultaneously or were sequential, with one disorder secondary to the other. ${ }^{66}$ A longitudinal study is therefore worth consideration.

Many studies have reported ${ }^{18,36,37,67}$ that anxiety and depressive symptoms are better predictors of quality of life than lung function parameters. Depression is associated with reduced social interaction and role functioning. ${ }^{38,43}$ Other studies have identified physical disability associated with depressive symptoms. ${ }^{18,19,20}$ Further, findings by Wells et al. ${ }^{68}$ confirm that depressive symptoms are related to subjects' functional wellbeing. It is a common clinical scenario that many COPD patients present with sleep disturbance, reduced energy level, difficulties in performing daily activities and reduced social interaction. Attributing such symptoms purely to COPD may mean that the diagnosis of depression is overlooked. ${ }^{19} \mathrm{~A}$ standard clinical interview will often fail to identify depression in chronic medical illness: the use of a psychiatric screening questionnaire in these circumstances is strongly recommended. ${ }^{32}$

\section{Depression in COPD and carers}

Keele-Card et al. ${ }^{69}$ examined loneliness and depression in a sample of 30 COPD patients and their spouses. Their findings suggest that there was no difference in mean scores of loneliness and depression between the two groups. Similar findings were reported by Meara et al. ${ }^{70}$ who studied the prevalence of depression in elderly Parkinson's patients $(64 \%)$, their spouses and carers (34\%). In a community survey, Livingston et al. ${ }^{71}$ compared the prevalence of depressive symptoms in carers with that in co-residents of elderly people with dementia, depression or physical disability. Their findings revealed a higher prevalence of depressive symptoms in carers than in co-residents $(24 \%$ c.f. $11 \%, \mathrm{p}<0.05)$ and that symptoms were most common in women caring for dementia patients. Similar findings have also been observed in carers of stroke patients. ${ }^{72}$ Depression in a patient with COPD may trigger depression in a carer but the reverse may also be true. For example, in prognostic studies of depression in psychiatric practice, depression in a carer is strongly correlated with poor outcome, ${ }^{73}$ and the belief by a carer that a depressed person is 'putting it on' also has a major negative effect on the outcome of depression. ${ }^{74}$ These findings have not been reproduced in patients with physical disability such as COPD, but there seems little reason to deny the existence of a 'vicious circle' in this patient group as well.

Interestingly, the present research ${ }^{67}$ has suggested that elderly subjects with COPD who live alone seem better satisfied with their lives than those who live with their spouses or relatives. This may however have been a survival or migration effect, those with more severe illness needing con- 
tinued help from 'live-in' carers. Although psychosocial support plays an important role in the ability of COPD patients to maintain independent living, this may depend on the quality rather than the quantity of support available. Moreover, COPD patients may have a wider range of needs, some of which may be complex, as the illness affects various aspects of their lives in its progression. Psychosocial factors, such as a poor relationship with one's spouse, have been implicated in the prognosis of depression in old age. ${ }^{75}$ Rehabilitation programmes should address these issues.

The wellbeing of carers is vitally important and can influence the carer's ability to provide care. For health care professionals planning long-term strategies for their patients, the welfare of the carers should be considered in terms of respite care or support in the community, and carer (as well as patient) education.

\section{Health-care utilization in depressed patients with COPD}

Poor general health, exacerbation and frequent hospitalization is the fate of many COPD patients. Retrospective uncontrolled studies suggest that health care utilization in depressed patients is far higher than that in non-depressed patients. ${ }^{65}$ These findings merely suggest that depression is associated with longer treatment spells in the hospital after recovering from acute exacerbations, but do not tell us what other factors might be associated with delayed discharge. Regueiro et al. ${ }^{76}$ carried out an extensive study of 866 COPD patients admitted with acute exacerbations. Patients were divided into two groups, to be cared for either by a pulmonologist or a generalist. Their findings suggest no difference between the healthcare costs or survival of the two groups. Prospective controlled studies are required to confirm or refute the effect of emotional status on health-care use in COPD, and to address the value of the multidisciplinary team in supporting and resettling the patient in the community.

\section{Conclusion}

Clinical anxiety and depressive symptoms are common in patients with COPD. They are often undiagnosed and untreated in this patient group. Those with depressive symptoms are usually more physically disabled and have greater impairment of their quality of life. This argues for improved detection of depression and for appropriate intervention for anxiety and depressive symptoms in patients with COPD. Such strategies should be multi modal, i.e. involving the physical, psychological and social domains, and should closely involve carers. There has been little evaluation of the treatment of depression associated with COPD.

\section{Acknowledgement}

Our thanks to Barbara Tomenson, statistician at the Department of Psychiatry, Manchester Royal Infirmary, for guidance with the meta-analysis.

\section{References}

1 Lcasse Y, Brooks D, Goldstein RS. Trends in the epidemiolgy of COPD in Canada, 1980 to 1995. Chest 1999; 116: 306-13.

2 Office of Population Censuses and Surveys. Mortality statistics, cause: England and Wales 1992. London: HMSO, 1993.

3 Williams SJ, Bury M. Impairment, disability and handicap in chronic illness. Soc Sci Med 1989; 29: 609-16.

4 Guyatt GH, Berman LB, Townsend M, Pugsley SO, Chambers LW. A measure of quality of life for clinical trials in chronic lung disease. Thorax 1987; 42: 773-77

5 Conolly MJ. Obstructive airways disease: a hidden disability in the aged. Age Ageing 1996; 25 : 265-67.

6 Royal College of Physicans. Disabling chest disease: prevention and care. J Roy Coll Phys Lond 1981; 15: 69-87.

7 Renwick DS, Connolly MJ. Prevalence and treatment of chronic airways obstruction in adults over the age of 45. Thorax 1996; 51: 164-68.

8 Dow L, Coggon D, Osmond C, Holgate ST. A population survey of respiratory symptoms in the elderly. Eur Respir J 1991; 4: 267-72.

9 Banerjee DK, Lee GS, Malik SK, Daly S. Underdiagnosis of asthma in the elderly. $\mathrm{Br} J \mathrm{Dis}$ Chest 1987; 81: 23-29.

10 Hunt A. The elderly at home. A study of people aged sixty-five and over living in the community in England in 1976. Office of Population Censuses and Surveys. London: HMSO, 1976.

11 American Thoracic Society. Standards for the diagnosis and care of patients with chronic obstructive pulmonary disease. Am J Respir Crit Care Med 1995; 152: 77-120.

12 Ruuskanen JM, Ruoppila I. Physical activity and 
psychological wellbeing among people aged 65 to 84 years. Age Ageing 1995; 292-96

13 Greenberg PE, Sisitsky T, Kessler RC et al. The economic burden of anxiety disorders in the 1990s. J Clin Psychiatry 1999; 60: 427-35.

14 Lyness JM, King DA, Cox C, Yoediono Z, Caine ED. The importance of subsyndromal depression in older primary care patients: prevalence and associated functional disability. $J \mathrm{Am}$ Geriatr Soc 1999; 47: 647-52.

15 Koenig HG, Shelp F, Goli V, Cohen HJ, Blazer DJ. Survival and health care utilization in elderly medical inpatients with major depression. J Am Geriatr Soc 1989; 37: 599-606.

16 Bosley CM, Corden ZM, Rees PJ, Cochrane GM. Psychological factors associated with the use of home nebulized therapy for COPD. Eur Respir J 1996; 9: 2346-50.

17 Light RW, Merill EJ, Despars JA, Gordon GH, Mutalipassi LR. Prevalence of depression and anxiety in patients with COPD. Chest 1985; 87: 35-38.

18 McSweeny AJ, Grant I, Heaton RK, Adams KM, Timms RM. Life quality of patients with chronic obstructive pulmonary disease. Ann Intern Med 1982; 142: 473-78.

19 Yohannes AM, Roomi J, Baldwin RC, Connolly MJ. Depression in elderly outpatients with disabling chronic obstructive pulmonary disease. Age Ageing 1998; 27: 155-60.

20 Jones PW, Baveystock CM, Littlejohns P. Relationships between general health measured with the Sickness Impact Profile and respiratory symptoms, physiological measures, and mood in patients with chronic airflow limitation. Am Rev Respir Dis 1989; 140: 1538-43.

21 Eiser N, West C, Evans S, Jeffers A, Quirk F. Effects of psychotherapy in moderately severe COPD: a pilot study. Eur Respir J 1997; 10: 1581-84.

22 White RJ, Rudkin ST, Ashley J et al. Outpatient pulmonary rehabilitation in severe chronic obstructive pulmonary disease. J Roy Coll Phys Lond 1997; 31: 541-45.

23 Ries AL, Kaplan RM, Limberg TM, Prewit L. Effects of pulmonary rehabilitation on physiologic and psychosocial outcomes in patients with chronic obstructive pulmonary disease. Ann Intern Med 1995; 122: 823-32.

24 Borak J, Silwinski P, Piaseckl Z, Zielinski J. Psychological status of COPD patients on longterm oxygen therapy. Eur Respir J 1991; 4: 59-62.

25 Engstrom C-P, Persson L-O, Larsson S, Ryden A, Sullivan M. Functional status and wellbeing in chronic obstructive pulmonary disease with regard to clinical parameters and smoking: a descriptive and comparative study. Thorax 1996; 51:

825-30.

26 Isoaho R, Keistinen T, Laippala P, Kivela S-L. Chronic obstructive pulmonary disease and symptoms related to depression in elderly persons. Psychol Rep 1995; 76: 287-97.

27 Yellows PM, Alpers JH, Bowden JJ, Bryant GD, Ruffin RE. Psychiatric morbidity in patients with chronic airflow obstruction. Med J Aust 1987; 146: 305-07.

28 Karajgi B, Rifkin A, Doddi S, Kolli R. The prevalence of anxiety disorders in patients with chronic obstructive pulmonary disease. Am J Psychiatry 1990; 147: 200-01.

29 Cummings JL. Depression and Parkinson's disease: a review. Am J Psychiatry 1992;149:443-54.

30 Gordon WA, Hibbard MR. Poststroke depression: an examination of the literature. Arch Phys Med Rehabil 1997; 78: 658-63.

31 van Ede I, Yzermans CJ, Brouwer HJ. Prevalence of depression in patients with chronic obstructive pulmonary disease: a systematic review. Thorax 1999; 54: 688-92.

32 Jackson R, Baldwin RC. Detecting depression in elderly medically ill patients: the use of the Geriatric Depression Scale compared with medical and nursing observations. Age Ageing 1993; 22: 349-53.

33 Paykel ES, Hart D, Priest RG. Changes in public attitudes to depression during the Defeat Depression campaign. Br J Psychiat 1998; 173: 519-22.

34 Sims A. The scar that is more than skin deep: the stigma of depression. Br J Gen Pract 1993; 43: 30-31.

35 Gift AG, McCrone SH. Depression in patients with COPD. Heart Lung 1993; 22: 289-89.

36 Agle DP, Baum GL. Psychological aspects of chronic obstructive pulmonary disease. Med Clin N Am 1977; 61: 749-58.

37 Prigatano GP, Wright EC, Levin D. Quality of life and its predictors in patients with mild hypoxemia and chronic obstructive pulmonary disease. Arch Intern Med 1984; 144: 1613-19.

38 Sandhu HS. Psychosocial issues in chronic obstructive pulmonary disease. Clin Chest Med 1986; 7: 629-42.

39 Sexton DL, Munro BH. Impact of a husband's chronic illness (COPD) on the spouse's life. Res Nurs Health 1985; 8: 83-90.

40 Copeland JRM, Dewey ME, Wood N, Searle R, Davidson IA, McWilliam C. Range of mental illness among the elderly in the community: prevalence in Liverpool using the GMS-AGECAT package. Br J Psychiatry 1987; 150: 815-23.

41 Livingston G, Hawkins A, Graham N, Blizard B, Mann A. The Gospel Oak study: prevalence rate 
of dementia, depression and activity limitation among elderly residents in inner London. Psychol Med 1990; 20: 137-46.

42 Ahto M, Isoaho R, Puolijoki H, Laippala P, Romo M, Kivela S-K. Coronary heart disease and depression in the elderly - a population-based study. Fam Pract 1997; 14: 436-45.

43 Dudley DL, Glaser EM, Jorgenson BN, Logan DL. Psychosocial concomitants to rehabilitation in chronic obstructive pulmonary disease. Part 2. Psychosocial treatment. Chest 1980; 77: 544-51.

44 Schlenk EA, Erlen JA, Dunbar-Jacob J. Healthrelated quality of life in chronic disorders: a comparison across studies using the MOS SF-36. Qual Life Res 1998; 7: 57-65.

45 Okubadejo AA, Jones PW, Wedzicha JA. Quality of life in patients with chronic obstructive pulmonary disease and severe hypoxaemia. Thorax 1996; 51: 44-47.

46 Incalzi RA, Chiappini F, Fuso L, Torrice MP, Gemma A, Pistelli R. Predicting cognitive decline in patients with hypoxaemic COPD. Respir Med 1998; 92: 527-33.

47 Monso E, Fiz JM, Izquierdo J et al. Quality of life in severe chronic obstructive pulmonary disease: correlation with lung and muscle function. Respir Med 1998; 92: 221-27.

48 Strom K. Oral corticosteroid treatment during long-term oxygen therapy in chronic obstructive pulmonary disease: a risk factor for hospitalization and mortality in women. Respir Med 1998; 92: 50-56.

49 British Thoracic Society. Guidelines for the management of chronic obstructive pulmonary disease. Thorax 1997; 52 (suppl 5): 1-28.

50 Wijkstra PJ, Altena RV, Kraan J, Otten V, Postma DS, Koeter GH. Quality of life in patients with chronic obstructive pulmonary disease improves after rehabilitation at home. Eur Respir J 1994; 7: 269-73.

51 Singh SJ, Smith DL, Hyland ME, Morgan MDL. A short outpatient pulmonary rehabilitation: immediate and long-term effects of on exercise performance and quality of life. Respir Med 1998; 92: 1146-54.

52 Strijbos JH, Postma DS, van Altena R, Gimeno R, Koeter GH. A comparison between an outpatient hospital-based pulmonary rehabilitation program and a home-care pulmonary rehabilitation program in patients with COPD. Chest 1996; 109: 366-72.

53 Sassi-Dambron DE, Eakin EG, Ries AL, Kaplan RM. Treatment of dyspnoea in COPD: a controlled clinical trial of dyspnoea management strategies. Chest 1995; 107: 724-29.

54 Gift AG, Moore T, Soeken K. Relaxation to reduce dyspnoea and anxiety in COPD patients.
Nurs Res 1992; 42: 242-46.

55 Emery CF, Schein RL, Hauck ER, MacIntyre NR. Psychological and cognitive outcome of a randomised trial of exercise among patients with chronic obstructive pulmonary disease. Health Psychol 1998; 17: 232-40.

56 Devine EC, Pearcy J. Meta-analysis of the effects of psychoeducational care in adults with chronic obstructive pulmonary disease. Patient Educ Couns 1996; 29: 167-78.

57 Tougaard L, Krone T, Sorknaes A, Ellegaard H. Economic benefits of teaching patients with chronic obstructive pulmonary disease. Lancet 1992; 339: 1517-20.

58 Seemungal TAR, Donaldson GC, Paul EA, Bestall JC, Jeffries DJ, Wedzicha JA. Effect of exacerbation on quality of life in patients with chronic obstructive pulmonary disease. Am J Respir Crit Care Med 1998; 157: 1418-22.

59 Gallefoss F, Bakke PS, Kjaersgaard P. Quality of life assessment after patient education in a randomised controlled study on asthma and chronic obstructive pulmonary disease. Am J Respir Crit Care Med 1999; 159: 812-17.

60 Gordon GH, Michiels TM, Mahutte CK, Light RW. Effect of desipramine on control of ventilation and depression scores in patients with severe chronic obstructive pulmonary disease. Psychiatry Res 1985; 15: 25-32.

61 Koenig HG, Goli V, Shelp F et al. Antidepressant use in elderly medical inpatients: lessons from an attempted clinical trial. J Gen Intern Med 1989; 4: 498-505.

62 Evans M, Hammond M, Wilson K, Lye M, Copeland J. Placebo-controlled treatment trial of depression in elderly physically ill patients. Int $J$ Geriatr Psychiatry 1997; 12: 817-24.

63 Yohannes AM, Connolly MJ, Baldwin RC. Six months follow-up of antidepressant drug therapy in depressed elderly patients with chronic obstructive pulmonary disease. Int J Geriatr Psychiat (in press).

64 Copeland JRM, Kelleher MJ, Kellett JM et al. A semi-structured clinical interview for the assessment of diagnosis and mental state in the elderly: the Geriatric Mental State Schedule I.

Development and reliability. Psychol Med 1976; 6: 439-49.

65 Yohannes AM, Baldwin RC, Connolly MJ. Prevalence of clinical anxiety in elderly patients with chronic obstructive pulmonary disease. Age Ageing 1999; 28 (suppl 2): 113.

66 Flint AJ. Epidemiology and comorbidity of anxiety disorders in the elderly. Am J Psychiatry 1994; 151: 640-49.

67 Yohannes AM, Roomi J, Waters K, Connolly MJ. Quality of life in elderly patients with COPD: 
measurement and predictive values. Respir Med 1998; 92: 1231-36.

68 Wells KB, Stewart A, Hays RD et al. The functioning and wellbeing of depressed patients. JAMA 1989; 262: 914-19.

69 Keele-Card G, Foxall MJ, Barron CR. Loneliness, depression, and social support of patients with COPD and their spouses. Pub Health Nurs 1993; 10: 245-51.

70 Meara J, Mitchelmore E, Hobson P. Use of the GDS-15 Geriatric Depression Scale as a screening instrument for depressive symptomatology in patients with Parkinson's disease and their carers in the community. Age Ageing 1999; 28: 35-38.

71 Livingston G, Manela M, Katona C. Depression and other psychiatric morbidity in carers of elderly people living at home. BMJ 1996; 312: 153-56.

72 Carnwath TCM, Johnson DAW. Psychiatric morbidity among spouses of patients with stroke. BMJ 1987; 294: 409-11.
73 Hinrichsen GA, Hernandez NA. Factors associated with recovery from and relapse into major depressive disorder in the elderly. Am J Psychiat 1993 150: 1820-25.

74 Casten RJ, Rovner BW, Shmuely-Dulitki Y, Pasternak RE, Pelchat R, Ranen N. Predictors of recovery from major depression among general psychiatry inpatients: the importance of caregiver's beliefs. Int Psychogeriatr 1999 11: 149-157.

75 Kivela S-L, Kongas-Saviaro P, Laippala P, Pahkala K, Kesti E. Social and psychosocial factors predicting depression in old age: a longitudinal study. Int Psychogeriatr 1996; 8: 635-44.

76 Regueiro CR, Hamel MB, Davis RB, Desbiens N, Connors AF, Phillips RS. A comparison of generalist and pulmonologist care for patients hospitalised with severe chronic obstructive pulmonary disease: resource intensity, hospital costs, and survival. Am J Med 1998; 105: 366-72. 